\title{
Diversidade fenotípica e eficiência simbiótica de estirpes de Bradyrhizobium spp. de solos da Amazônia
}

\author{
Adriana Silva Lima(1), João Paulo Andrade Resende Pereira(1) e Fátima Maria de Souza Moreira(1)
}

(1)Universidade Federal de Lavras, Dep. de Ciência do Solo, Caixa Postal 3037, CEP 37200-000 Lavras, MG. E-mail: adrianalima@navinet.com.br, joaopauloufla@yahoo.com.br, fmoreira@ufla.br

\begin{abstract}
Resumo - Este trabalho teve como objetivo avaliar a diversidade fenotípica e a eficiência simbiótica de estirpes de Bradyrhizobium, isoladas de solos da Amazônia, sob diferentes sistemas de uso da terra (monocultura, capoeira, pastagem, floresta e sistema agroflorestal). A análise dos perfis de proteína total de 46 estirpes, obtidos por eletroforese em gel de poliacrilamida (SDS-PAGE), mostrou grande diversidade, tendo formado 11 grupos com similaridade acima de $80 \%$. Apenas um dos grupos continha a estirpe referência de B. elkanii: BR29, recomendada como inoculante para soja. Vinte e duas estirpes testadas em vasos de Leonard, com caupi (Vigna unguiculata (L.) Walp.), induziram à produção de matéria seca e ao acúmulo de nitrogênio, na parte aérea da planta, e à eficiência relativa superiores aos da testemunha (sem N e sem inoculação). Entre as estirpes testadas, 13 induziram à produção de matéria seca e à eficiência relativa similares às da testemunha nitrogenada (com N, sem inoculação); cinco estirpes induziram a acúmulo de N superior ao da testemunha nitrogenada. Essas populações nativas são constituídas por grande diversidade de estirpes, com eficiência simbiótica variável, algumas das quais podem ser recomendadas para testes de eficiência agronômica.
\end{abstract}

Termos para indexação: Vigna unguiculata, fixação biológica de $\mathrm{N}_{2}$, bactérias nodulíferas.

\section{Phenotypic diversity and symbiotic efficiency of Bradyrhizobium spp. strains from Amazonian soils}

\begin{abstract}
This work aimed to evaluate the phenotypic diversity and symbiotic efficiency of Bradyrhizobium strains isolated from Amazonian soils, under different land use systems (crop, fallow, pasture, forest and agroforestry system). Total protein profiles obtained by polyacrylamide gel electrophoresis (SDS-PAGE) of 46 strains showed great diversity, while 11 groups presented similarity above $80 \%$. One of these groups contained the reference strain of B. elkanii: BR29, recommended as soybean inoculant. Twenty-two strains, tested in Leonard jars for symbiotic efficiency with Vigna unguiculata (L.) Walp. (cowpea) produced shoot dry matter, N-content, and relative efficiency higher than the control (without $\mathrm{N}$, with inoculation). Production of shoot dry matter and relative efficiency were induced by 13 strains in a way similar to the $\mathrm{N}$-control (with $\mathrm{N}$, without inoculation); five strains induced higher nitrogen content than $\mathrm{N}$-control. Native populations comprise high diversity of strains with variable symbiotic efficiency, and some of them could be recommended for agronomic efficiency assays.
\end{abstract}

Index terms: Vigna unguiculata, biological $\mathrm{N}_{2}$ fixation, Leguminosae nodulating bacteria.

\section{Introdução}

A Bacia Amazônica possui cerca de sete milhões de quilômetros quadrados e é constituída por uma floresta exuberante, com grande diversidade que, comparada com outras regiões brasileiras, ainda é pouco explorada para a produção agrícola. A intensificação da interferência antropogênica resulta na perda e alteração da diversidade, respectivamente acima e abaixo do solo e pode, conseqüentemente, influenciar os processos bio- lógicos importantes para o bom funcionamento do ecossistema.

Pela sua diversidade e dinâmica, e por estarem continuamente mudando e se adaptando às alterações ambientais, os microrganismos constituem indicadores sensíveis às mudanças oriundas do manejo do solo (Kennedy \& Papendick, 1995) e do tipo de cobertura vegetal (Prasad et al., 1994).

A diversidade biológica é definida como a variabilidade entre as espécies de organismos vivos e pode ser 
medida em vários níveis taxonômicos (família, gênero, intraespécies etc.) ou, ainda, em termos de determinadas características genéticas ou fenotípicas (morfológicas, bioquímicas, fisiológicas, simbióticas) (Moreira \& Siqueira, 2002). O conhecimento sobre a variedade das bactérias que nodulam leguminosas é ainda limitado, por falta de conhecimento sobre os microssimbiontes da grande maioria dessas espécies vegetais, principalmente as tropicais. Nas últimas décadas, estudos revelaram uma grande diversidade de rizóbios de espécies florestais, até então desconhecida, inclusive no gênero Bradyrhizobium (Moreira et al., 1993; Dupuy et al., 1994; Willems et al., 2000).

A caracterização de uma bactéria envolve a descrição de muitas propriedades relativas à morfologia, cultivo, nutrição, bioquímica, metabolismo, ácidos nucléicos, patogenicidade e ecologia, as quais são pré-requisitos para a identificação e base da sistemática desse grupo de organismos. Estudos têm mostrado o potencial da eletroforese de proteínas para o estudo da diversidade de microrganismos em geral (Kampfer et al., 1995), na caracterização de diferentes estirpes de bactérias fixadoras de $\mathrm{N}_{2}$ (Dreyfus et al., 1988; Moreira et al., 1993; Dupuy et al., 1994; Lajudie et al., 1998; Pereira, 2000), e de fungos ectomicorrízicos dos gêneros Pisolithus (Souza, 2000) e Suillus (Keller, 1992). Além disso, foi demonstrado que há correlação entre a análise de hibridação DNA-DNA e o perfil eletroforético de proteínas (Vandamme et al., 1990; Kampfer, 1995).

O feijão caupi é uma cultura de destaque na economia do Norte e Nordeste do Brasil, pois representa cerca de 70\% do feijão produzido (Vieira, 1989) e é o principal alimento protéico e energético do homem do campo.

Essa espécie apresenta alta rusticidade e adaptabilidade à estiagem prolongada e capacidade de se desenvolver em solo de baixa fertilidade (Oliveira \& Carvalho, 1988). Além disso, seus resíduos podem contribuir com $\mathrm{N}$ e outros nutrientes, quando incorporados ao solo ou quando fornecidos como alimento aos animais (Brito, 1992).

Apesar de ser promíscuo, pois nodula com vários gêneros de rizóbio (Lewin et al., 1987), a estirpe recomendada como inoculante para o caupi (BR2001/SEMIA 6145) até 2004 (Relare, 2004) pertence ao gênero Bradyrhizobium. Essa estirpe foi substituída por
UFLA03-84, INPA03-11B e BR3267, na última Relare (2004), pois apresentam eficiência agronômica superior (Martins et al., 2003; Lacerda et al., 2004).

A eficiência das bactérias fixadoras de nitrogênio, que estabelecem simbiose com leguminosas, e sua capacidade de sobreviver e formar nódulos no solo dependem de fatores genéticos inerentes aos simbiontes e da interação com fatores edáfo-climáticos (Moreira \& Siqueira, 2002). A diversidade, inclusive de leguminosas, encontrada nos vários sistemas de uso da terra (capoeira, pastagem tradicional, sistema agroflorestal, floresta e monocultura), na Amazônia, pode abrigar também uma grande variabilidade de rizóbios (Moreira et al., 1993; Pereira, 2000), adaptados a condições de baixos valores de $\mathrm{pH}$ e temperaturas elevadas (predominantes nos solos brasileiros), cujo imenso potencial ainda é pouco conhecido.

O objetivo deste trabalho foi avaliar a diversidade fenotípica e a eficiência simbiótica de estirpes de Bradyrhizobium, isoladas de áreas da Amazônia, sob diferentes sistemas de uso da terra.

\section{Material e Métodos}

\section{Estirpes}

As quarenta e seis estirpes de rizóbio estudadas foram obtidas, utilizando-se siratro como planta isca, com inoculação de suspensões de amostras de solo diluídas para contagem de rizóbio, em sítios da Amazônia sob cinco sistemas de uso da terra (SUT): monoculturas, capoeira, pastagem, floresta e sistema agroflorestal (Pereira, 2000) (Tabelas 1 e 2). As estirpes foram isoladas em meio 79 (Fred \& Waksman, 1928) e mantidas sob refrigeração (a $4^{\circ} \mathrm{C}$ e a $-80^{\circ} \mathrm{C}$ ), cujas características culturais são típicas de Bradyrhizobium (Tabela 3), como: crescimento lento (mais de seis dias para aparecimento de colônias isoladas), reação alcalina e de pouca a média produção de polissacarídeos extracelulares (goma) em meio de cultura 79. As estirpes foram isoladas de diluições do solo que variaram de $5^{-1}$ a $5^{-6}$. Foram comparadas a estirpes tipo e referência de Bradyrhizobium spp.: SEMIA 5019/BR29, estirpe recomendada como inoculante para a soja (Glycine max (L.) Merrill), pela Relare (2004), e identificada como 
Tabela 1. Sistema de uso da terra (SUT), principais características, procedência e estirpes de Bradyrhizobium estudadas.

\begin{tabular}{|c|c|c|c|}
\hline Sistema de uso da terra ${ }^{(1)}$ & Principais características & $\begin{array}{c}\text { Procedência } \\
\text { Município, Estado }\end{array}$ & Estirpes \\
\hline Monocultura - feijão (M1) & $\begin{array}{l}\text { Feijão depois do plantio de milho no fim de um ano de } \\
\text { queimada. Muitos galhos e tocos. }\end{array}$ & Theobroma, RO & UFLA04-0110, UFLA04-0151 \\
\hline Monocultura - mandioca (M2) & $\begin{array}{l}\text { Mandioca em presença de plantas daninhas, depois de } \\
\text { três anos de plantio (arroz, feijão, entre outras). }\end{array}$ & Theobroma, RO & $\begin{array}{l}\text { UFLA04-0204 UFLA04-0208, UFLA04-0212, } \\
\text { UFLA04-0214, UFLA04-0225, UFLA04-0230 }\end{array}$ \\
\hline Monocultura - arroz (M3) & $\begin{array}{l}\text { Um ano depois da queimada. Arroz já colhido, com } \\
\text { algumas plantas e palhas presentes. Feijão plantado em } \\
\text { alguns lugares. Muitos troncos, tocos e galhos. } \\
\text { Significativo brotamento e presença de ervas daninhas. }\end{array}$ & Pedro Peixoto, AC & UFLA04-1521 \\
\hline Capoeira (C1) & Recobrimento natural de três anos. & Theobroma, RO & $\begin{array}{l}\text { UFLA04-0304, UFLA04-03114, UFLA04-0321, } \\
\text { UFLA04-0337, UFLA04-0338, UFLA04-0339, } \\
\text { UFLA04-0355 }\end{array}$ \\
\hline Capoeira (C2) & $\begin{array}{l}\text { Recobrimento natural de dois anos, depois do plantio } \\
\text { de feijão e milho. }\end{array}$ & Theobroma, RO & UFLA04-0401, UFLA04-0417 \\
\hline Capoeira (C3) & $\begin{array}{l}\text { Recobrimento de cinco anos. Árvores muito } \\
\text { desenvolvidas. }\end{array}$ & Pedro Peixoto, AC & UFLA04-1309, UFLA04-1332 \\
\hline Pastagem (P1) & Pastagem de Brachiaria brizantha com oito a dez anos. & Theobroma, RO & UFLA04-0546, UFLA04-0459 \\
\hline Pastagem (P2) & $\begin{array}{l}\text { Idade de dez anos. Algumas árvores e tocos. Muitas } \\
\text { touceiras de capim. }\end{array}$ & Jí-Paraná, RO & $\begin{array}{l}\text { UFLA04-0820, UFLA04-0821, UFLA04-0824, } \\
\text { UFLA04-0849, UFLA04-0850, UFLA04-0885, } \\
\text { UFLA04-08113, UFLA04-08118 }\end{array}$ \\
\hline Pastagem (P3) & Limpa, com presença de poucos tocos. & Pedro Peixoto, AC & UFLA04-1272 \\
\hline Floresta (F1) & $\begin{array}{l}\text { Desmatamento seletivo, liteira muito espessa com } \\
\text { muitos galhos mortos e tocos. }\end{array}$ & Theobroma, RO & UFLA04-0640 \\
\hline Floresta (F2) & $\begin{array}{l}\text { Floresta pouco desenvolvida. Solo com pedregosidade } \\
\text { e baixa fertilidade. }\end{array}$ & Pedro Peixoto, AC & UFLA04-1406, UFLA04-1413, UFLA04-1417 \\
\hline Sistema agroflorestal (A1) & $\begin{array}{l}\text { Café com seringueira ( } 12 \text { anos). Cobertura vegetal de } \\
70 \% \text {, com algumas espécies de árvores pioneiras. } \\
\text { Poucos galhos mortos ou tocos. }\end{array}$ & Jí-Paraná, RO & $\begin{array}{l}\text { UFLA04-0903, UFLA04-0917, UFLA04-0918, } \\
\text { UFLA04-0924, UFLA04-0926, UFLA04-0957, } \\
\text { UFLA04-0958 }\end{array}$ \\
\hline Sistema agroflorestal (A2) & $\begin{array}{l}\text { Cupuaçu, castanha-do-Brasil e pupunha (sete anos), } \\
\text { cobertura vegetal de } 90 \% \text {, liteira fina com muitos } \\
\text { galhos e tocos. }\end{array}$ & $\mathrm{RECA}^{(2)}, \mathrm{AC}$ & $\begin{array}{l}\text { UFLA04-1001, UFLA04-1018, UFLA04-1019, } \\
\text { UFLA04-1020 }\end{array}$ \\
\hline
\end{tabular}

(1)Código de identificação. ${ }^{(2)}$ RECA: reflorestamento econômico consorciado adensado.

Tabela 2. Análise de amostras de solos da Amazônia, sob diferentes sistemas de uso da terra: monoculturas de feijão (M1), mandioca (M2) e arroz (M3), capoeiras (C1, C2 e C3), pastagens (P1, P2 e P3), florestas (F1 e F2) e sistema agroflorestal (A1 e A2).

\begin{tabular}{|c|c|c|c|c|c|c|c|c|c|c|c|c|c|}
\hline Análise & M1 & M2 & M3 & $\mathrm{C} 1$ & $\mathrm{C} 2$ & C3 & $\mathrm{P} 1$ & $\mathrm{P} 2$ & P3 & F1 & $\mathrm{F} 2$ & A1 & $\mathrm{A} 2$ \\
\hline pH (água) & 6,6 & 4,6 & 4,8 & 4,7 & 5,4 & 6,1 & 5,3 & 6,1 & 5,1 & 4,1 & 4,8 & 5 & 5,7 \\
\hline $\mathrm{P}\left(\mathrm{mg} \mathrm{dm}^{-3}\right)$ & 14 & 1 & 4 & 1 & 3 & 4 & 2 & 2 & 1 & 2 & 3 & 1 & 2 \\
\hline $\mathrm{K}\left(\mathrm{mg} \mathrm{dm}^{-3}\right)$ & 41 & 22 & 103 & 39 & 58 & 39 & 58 & 75 & 95 & 33 & 83 & 94 & 58 \\
\hline $\mathrm{Ca}\left(\mathrm{mmol}_{\mathrm{c}} \mathrm{dm}^{-3}\right)$ & 40 & 8 & 22 & 10 & 23 & 57 & 16 & 29 & 13 & 7 & 15 & 24 & 23 \\
\hline $\mathrm{Mg}\left(\mathrm{mmol}_{\mathrm{c}} \mathrm{dm}^{-3}\right)$ & 17 & 8 & 16 & 6 & 9 & 12 & 4 & 3 & 11 & 2 & 14 & 12 & 11 \\
\hline $\mathrm{Al}\left(\mathrm{mmol}_{\mathrm{c}} \mathrm{dm}^{-3}\right)$ & 0 & 11 & 15 & 9 & 2 & 0 & 4 & 0 & 4 & 15 & 19 & 10 & 0 \\
\hline $\mathrm{H}+\mathrm{Al}\left(\mathrm{mmol}_{\mathrm{c}} \mathrm{dm}^{-3}\right)$ & 17 & 50 & 88 & 56 & 29 & 19 & 36 & 19 & 29 & 70 & 110 & 79 & 23 \\
\hline $\mathrm{S}^{(1)}\left(\mathrm{mmol}_{\mathrm{c}} \mathrm{dm}^{-3}\right)$ & 58 & 17 & 41 & 17 & 33 & 70 & 21 & 39 & 26 & 10 & 31 & 38 & 35 \\
\hline $\left.\mathrm{T}^{(3)} \mathrm{mmol} \mathrm{dm}{ }^{-3}\right)$ & 75 & 67 & 129 & 73 & 62 & 89 & 57 & 58 & 55 & 80 & 141 & 117 & 58 \\
\hline $\mathrm{m}^{(4)}(\%)$ & 0 & 40 & 27 & 35 & 6 & 0 & 16 & 0 & 1,3 & 60 & 38 & 21 & 0 \\
\hline $\mathrm{V}^{(5)}(\%)$ & 77 & 25 & 32 & 23 & 54 & 79 & 37 & 67 & 48 & 12 & 22 & 33 & 61 \\
\hline Carbono $\left(\mathrm{g} \mathrm{kg}^{-1}\right)$ & 9 & 8 & 11 & 11 & 11 & 14 & 11 & 9 & 9 & 11 & 17 & 14 & 9 \\
\hline $\mathrm{MO}^{(6)}\left(\mathrm{Dag} \mathrm{kg}^{-1}\right)$ & 1,6 & 1,3 & 1,9 & 1,9 & 1,9 & 2,4 & 1,9 & 1,6 & 1,5 & 1,9 & 2,9 & 2,5 & 1,5 \\
\hline Areia $\left(\mathrm{g} \mathrm{kg}^{-1}\right)$ & 500 & 460 & 140 & 420 & 520 & 480 & 500 & 780 & 540 & 500 & 180 & 100 & 660 \\
\hline Silte $\left(\mathrm{g} \mathrm{kg}^{-1}\right)$ & 150 & 150 & 260 & 150 & 130 & 280 & 150 & 130 & 270 & 150 & 290 & 210 & 190 \\
\hline Argila $\left(\mathrm{g} \mathrm{kg}^{-1}\right)$ & 350 & 390 & 600 & 430 & 350 & 240 & 350 & 90 & 190 & 350 & 530 & 690 & 150 \\
\hline $\mathrm{Zn}\left(\mathrm{mg} \mathrm{dm}^{-3}\right)$ & 1,9 & 0,2 & 0,2 & 0,1 & 0,28 & 0,6 & 0,28 & 2,2 & 0,2 & 0,2 & 0,5 & 0,2 & 0,9 \\
\hline $\mathrm{Cu}\left(\mathrm{mg} \mathrm{dm}^{-3}\right)$ & 1 & 0,6 & 1,6 & 0,9 & 0,9 & 1 & 0,8 & 2,3 & 1 & 0,7 & 1,8 & 1,6 & 1,2 \\
\hline $\mathrm{Fe}\left(\mathrm{mg} \mathrm{dm}^{-3}\right)$ & 82 & 116 & 80 & 63 & 63 & 32 & 95 & 33 & 69 & 156 & 147 & 56 & 51 \\
\hline $\operatorname{Mn}\left(\mathrm{mg} \mathrm{dm}^{-3}\right)$ & 9 & 3 & 12 & 12 & 5 & 68 & 9 & 97 & 15 & 6 & 16 & 5 & 63 \\
\hline
\end{tabular}

${ }^{(1)}$ Soma de bases trocáveis. ${ }^{(2)} \mathrm{CTC}$ efetiva. ${ }^{(3)} \mathrm{CTC}$ em pH 7. (4)Saturação de Al da CTC efetiva. (5)Saturação de bases da CTC a pH 7. (6)Matéria orgânica. 
Bradyrhizobium elkanii; ATCC $10324^{\mathrm{T}}$, estirpe tipo de Bradyrhizobium japonicum; SEMIA 6145/BR2001, estirpe previamente recomendada pela Relare (2004) para inoculação em caupi; UFLA 03-170, estirpe de área reabilitada com bracatinga, após mineração com bauxita e com alta eficiência em vasos de Leonard (Motta, 2002) e vasos com solo (Lacerda et al., 2004); INPA-03-11B, estirpe isolada da Amazônia, eficiente para caupi em vasos de Leonard (Magalhães, 1986; Lacerda et al., 2004), vasos com solo e campo (Lacerda et al., 2004); e UFLA 03-84, estirpe de alta eficiência em caupi, em vasos de Leonard, com solo e em campo (Lacerda et al., 2004). As duas últimas são, atualmente, recomendadas como inoculantes para caupi pela Relare (2004).

Tabela 3. Características culturais de estirpes de Bradyrhizobium, isoladas de nódulos de siratro com inoculação de suspensões diluídas na base 5, de amostras de solo da Amazônia, sob diferentes sistemas de uso da terra (SUT).

\begin{tabular}{|c|c|c|c|c|c|c|c|c|}
\hline Estirpe & SUT & $\operatorname{Dias}^{(1)}$ & Diâmetro $^{(2)}$ & $\mathrm{pH}^{(3)}$ & Goma $^{(4)}$ & Cor & Indicador & $\mathrm{D}^{(5)}$ \\
\hline UFLA04-0110 & M1 & 6 & 1 & $\mathrm{AL}$ & 1 & Branca & Não & $5^{-1}$ \\
\hline UFLA04-0151 & M1 & 6 & $<1$ & $\mathrm{AL}$ & 1 & Branca & Não & $5^{-5}$ \\
\hline UFLA04-0204 & M2 & 6 & $1-2$ & $\mathrm{AL}$ & 2 & Branca & Não & $5^{-3}$ \\
\hline UFLA04-0208 & M2 & 6 & $>2$ & $\mathrm{AL}$ & 2 & Amarela & Não & $5^{-1}$ \\
\hline UFLA04-0212 & M2 & 7 & $1-2$ & $\mathrm{AL}$ & 1 & Branca & Não & $5^{-4}$ \\
\hline UFLA04-0214 & M2 & 6 & $1-2$ & $\mathrm{AL}$ & 1 & Branca & Não & $5^{-4}$ \\
\hline UFLA04-0225 & M2 & 6 & $1-2$ & $\mathrm{AL}$ & 2 aquosa & Branca & Não & $5^{-1}$ \\
\hline UFLA04-0230 & M2 & 6 & $<<1$ & $\mathrm{AL}$ & 1 & Branca & Não & $5^{-3}$ \\
\hline UFLA04-1521 & M3 & 11 & $<1$ & $\mathrm{AL}$ & 1 & Branca & Não & $5^{-2}$ \\
\hline UFLA04-0304 & $\mathrm{C} 1$ & 7 & $1-2$ & $\mathrm{AL}$ & 1 & Branca & Não & $5^{-1}$ \\
\hline UFLA04-0314 & $\mathrm{C} 1$ & 6 & $1-2$ & $\mathrm{AL}$ & 2 aquosa & Branca & Não & $5^{-2}$ \\
\hline UFLA04-0321 & $\mathrm{C} 1$ & 7 & $1-2$ & $\mathrm{AL}$ & 1 & Creme & Não & $5^{-3}$ \\
\hline UFLA04-0337 & $\mathrm{C} 1$ & 6 & $<1$ & $\mathrm{AL}$ & 1 & Creme & Não & $5^{-6}$ \\
\hline UFLA04-0338 & $\mathrm{C} 1$ & 6 & $1-2$ & $\mathrm{AL}$ & 2 aquosa & Branca & Não & $5^{-6}$ \\
\hline UFLA04-0339 & $\mathrm{C} 1$ & 7 & $<1$ & $\mathrm{AL}$ & 1 & Creme & Não & $5^{-6}$ \\
\hline UFLA04-0355 & $\mathrm{C} 1$ & 6 & $<1$ & $\mathrm{AL}$ & 1 & Creme & Não & $5^{-2}$ \\
\hline UFLA04-0401 & $\mathrm{C} 2$ & 6 & $1-2$ & $\mathrm{AL}$ & 2 & Branca & Não & $5^{-1}$ \\
\hline UFLA04-0417 & $\mathrm{C} 2$ & 6 & $1-2$ & $\mathrm{AL}$ & 2 & Branca & Não & $5^{-1}$ \\
\hline UFLA04-1309 & C3 & 6 & $<1$ & $\mathrm{AL}$ & 2 & Branca & Não & $5^{-2}$ \\
\hline UFLA04-1332 & C3 & 6 & $<1$ & $\mathrm{AL}$ & 2 & Branca & Não & $5^{-1}$ \\
\hline UFLA04-0546 & $\mathrm{P} 1$ & 6 & $1-2$ & $\mathrm{AL}$ & 2 & Branca & Não & $5^{-5}$ \\
\hline UFLA04-0559 & $\mathrm{P} 1$ & 6 & $1-2$ & $\mathrm{AL}$ & 2 & Branca & Não & $5^{-5}$ \\
\hline UFLA04-1272 & P3 & 8 & $<1$ & $\mathrm{AL}$ & 1 & Branca & Não & $5^{-2}$ \\
\hline UFLA04-0820 & $\mathrm{P} 2$ & 7 & $1-2$ & $\mathrm{AL}$ & 2 aquosa & Branca & Não & $5^{-2}$ \\
\hline UFLA04-0821 & $\mathrm{P} 2$ & 7 & $1-2$ & $\mathrm{AL}$ & 2 & Branca & Não & $5^{-2}$ \\
\hline UFLA04-0824 & $\mathrm{P} 2$ & 7 & $<1$ & $\mathrm{AL}$ & 1 & Branca & Não & $5^{-2}$ \\
\hline UFLA04-0917 & A1 & 7 & $<1$ & $\mathrm{AL}$ & 2 aquosa & Branca & Não & $5^{-4}$ \\
\hline UFLA04-0849 & $\mathrm{P} 2$ & 7 & $1-2$ & $\mathrm{AL}$ & 2 aquosa & Branca & Não & $5^{-4}$ \\
\hline UFLA04-0850 & $\mathrm{P} 2$ & 8 & $<1$ & $\mathrm{AL}$ & 1 & Amarela & Não & $5^{-4}$ \\
\hline UFLA04-0885 & $\mathrm{P} 2$ & 7 & $1-2$ & $\mathrm{AL}$ & 2 & Branca & Não & $5^{-6}$ \\
\hline UFLA04-8113 & $\mathrm{P} 2$ & 6 & $1-2$ & $\mathrm{AL}$ & 2 aquosa & Branca & Não & $5^{-3}$ \\
\hline UFLA04-8118 & $\mathrm{P} 2$ & 7 & $1-2$ & $\mathrm{AL}$ & & Amarela & Não & $5^{-4}$ \\
\hline UFLA04-0903 & A1 & 7 & $<1$ & $\mathrm{AL}$ & 2 aquosa & Branca & Não & $5^{-1}$ \\
\hline UFLA04-0918 & A1 & 7 & $<1$ & $\mathrm{AL}$ & 2 aquosa & Branca & Não & $5^{-4}$ \\
\hline UFLA04-0924 & A1 & 7 & $<1$ & $\mathrm{AL}$ & 2 aquosa & Branca & Não & $5^{-5}$ \\
\hline UFLA04-0926 & A1 & 7 & $<1$ & $\mathrm{AL}$ & 2 aquosa & Branca & Não & $5^{-6}$ \\
\hline UFLA04-0957 & A1 & 7 & $<1$ & $\mathrm{AL}$ & 1 & Branca & Não & $5^{-4}$ \\
\hline UFLA04-0958 & Al & 8 & $<1$ & $\mathrm{AL}$ & 1 & Branca & Não & $5^{-4}$ \\
\hline UFLA04-1001 & A2 & 7 & $1-2$ & $\mathrm{AL}$ & 1 & Branca & Não & $5^{-2}$ \\
\hline UFLA04-1018 & $\mathrm{A} 2$ & 7 & $<1$ & $\mathrm{AL}$ & 1 & Branca & Não & $5^{-3}$ \\
\hline UFLA04-1019 & $\mathrm{A} 2$ & 7 & $<1$ & $\mathrm{AL}$ & 1 & Branca & Não & $5^{-3}$ \\
\hline UFLA04-1020 & $\mathrm{A} 2$ & 7 & $1-2$ & $\mathrm{AL}$ & 2 aquosa & Branca & Não & $5^{-1}$ \\
\hline UFLA04-0640 & $\mathrm{F} 1$ & 10 & $<1$ & $\mathrm{AL}$ & 2 & Branca & Não & $5^{-3}$ \\
\hline UFLA04-1406 & $\mathrm{F} 2$ & 11 & $1-2$ & $\mathrm{AL}$ & 2 & Branca & Sim & $5^{-1}$ \\
\hline UFLA04-1413 & F2 & 8 & $1-2$ & $\mathrm{AL}$ & 1 & Branca & Não & $5^{-5}$ \\
\hline UFLA04-1417 & $\mathrm{F} 2$ & 9 & $1-2$ & $\mathrm{AL}$ & 2 & Branca & Não & $5^{-5}$ \\
\hline
\end{tabular}

${ }^{(1)}$ Tempo para aparecimento de colônias isoladas. (2)Diâmetro da colônia em mm. (3)A reação do meio de cultivo após crescimento de colônias foi alcalina (AL). ${ }^{(4)}$ Escala de notas de 1 a 4 para produção de goma: 1 (pouca) e 2 (média). ${ }^{(5)}$ Diluição da amostra de solo de onde foi isolada. 


\section{Análise de proteínas totais por eletroforese em} gel de poliacrilamida (SDS-PAGE)

As condições de cultivo foram rigorosamente padronizadas para todas as estirpes. As estirpes armazenadas cresceram em meio de cultura 79 por 4 dias. Após o crescimento por duas vezes sucessivas, em meio TY sólido, com mesmo tempo de incubação, foram inoculadas colônias isoladas em $50 \mathrm{~mL}$ de meio de cultura líquido TY. O crescimento bacteriano foi obtido após 4 dias, sob agitação constante de $120 \mathrm{rpm}$ a $28^{\circ} \mathrm{C}$. Em seguida, o meio com cada cultura foi centrifugado a $12.000 \mathrm{rpm}$ por $10 \mathrm{~min}$, à temperatura de $4^{\circ} \mathrm{C}$, o sobrenadante foi descartado e o "pellet" formado ressuspenso em tampão fosfato de sódio (NaPBS). Esse procedimento foi repetido duas vezes para lavagem das células. Setenta miligramas do "pellet" foi transferido para tubos de 1,5 mL; foi adicionado $0,9 \mathrm{~mL}$ do tampão da amostra (TTA) e $0,1 \mathrm{~mL}$ de SDS a 20\% para solubilização das proteínas. Essa mistura foi aquecida em banho-maria à $95^{\circ} \mathrm{C}$ por $10 \mathrm{~min}$. As amostras de proteínas solubilizadas foram centrifugadas a $12.000 \mathrm{rpm}$ por $10 \mathrm{~min}$, à temperatura de $4^{\circ} \mathrm{C}$, e $30 \mathrm{~mL}$ foram submetidas à eletroforese em gel de poliacrilamida (PAGE). Para tal, foi utilizado o método Laemmli (1970), com modificações descritas por Jackmam (1985), utilizadas para rizóbio por Moreira et al. (1993). Para eletroforese, utilizou-se um gel de sistema descontínuo, com concentração de poliacrilamida a 12\% para o gel separador, e a 5\% para o gel de concentração.

Uma matriz binária dos dados originais foi construída, com 13 cadeias polipeptídicas (bandas mais fortes), representativas dos 46 padrões gerados. Foi atribuído o valor 1 ou 0 , para indicar presença ou ausência de cada banda. Os padrões foram comparados por seu grau de similaridade estimado pelo coeficiente de Jacard $\left(\mathrm{S}_{\mathrm{j}}\right)$, agrupados pelo método UPGMA (average linkage clustering) e representados graficamente por um dendrograma obtido pelo programa NTSYS-pc, versão 2.0 .

\section{Análise da eficiência simbiótica}

Para avaliação da eficiência simbiótica foram selecionadas uma ou duas estirpes, representantes de cada sítio nos sistemas de uso da terra (SUT). As estirpes selecionadas foram as seguintes: UFLA04-0110, UFLA04-0151, UFLA04-0204, UFLA04-0230, UFLA04-03114, UFLA04-0321, UFLA04-0401,
UFLA04-0546, UFLA04-0559, UFLA04-0640, UFLA04-0849, UFLA04-0885, UFLA04-0917, UFLA04-0926, UFLA04-1001, UFLA04-1020, UFLA04-1272, UFLA04-1309, UFLA04-1332, UFLA04-1413, UFLA04-1417 e UFLA04-1521.

O experimento foi conduzido em vasos de Leonard (Vincent, 1970), em casa de vegetação, de setembro a outubro de 2002. O delineamento estatístico foi o inteiramente casualizado, com três repetições e 28 tratamentos, constituídos pela inoculação individual das 22 estirpes citadas anteriormente, e de quatro das estirpes referências (BR2001, INPA03-11B, UFLA03-84 e UFLA03-170), mais dois controles ( $\mathrm{N}$ mineral e testemunha sem $\mathrm{N}$ e sem inoculação). O nitrogênio foi aplicado em 3 parcelas, com intervalos de 10 dias, num total de $210 \mathrm{mg}$ de $\mathrm{N}\left(\mathrm{NH}_{4} \mathrm{NO}_{3}\right)$ por vaso.

A parte superior dos vasos de Leonard continha uma mistura de 1:1 de areia $(250 \mathrm{~mL})$ e de vermiculita (250mL), enquanto a inferior continha solução nutritiva de Jensen modificada $\left(\mathrm{K}_{2} \mathrm{HPO}_{4}, 0,2 \mathrm{~g} \mathrm{~L}^{-1}\right.$; $\mathrm{MgSO}_{4} .7 \mathrm{H}_{2} \mathrm{O}, 0,2 \mathrm{~g} \mathrm{~L}^{-1}$; NaCl, 0,2 g L ${ }^{-1}$; $\mathrm{CaHPO}_{4}$, $1 \mathrm{~g} \mathrm{~L}^{-1} ; \mathrm{FeCl}_{3} \cdot 6 \mathrm{H}_{2} \mathrm{O}, 0,1 \mathrm{~g} \mathrm{~L}^{-1}$ ), diluída quatro vezes. Após o preparo, os vasos foram autoclavados por uma hora, à pressão de $1,5 \mathrm{~kg} \mathrm{~cm}^{-2}$, a $127^{\circ} \mathrm{C}$. A solução nutritiva foi autoclavada por 20 min, à pressão de $1,5 \mathrm{~kg} \mathrm{~cm}^{-2}$ e a $127^{\circ} \mathrm{C}$. A cultivar de caupi utilizada foi a BR14 Mulato. As sementes empregadas foram desinfestadas, superficialmente, com etanol a $70 \%$ por 5 minutos, a e hipoclorito de sódio a 1\% por 3 minutos; em seguida, foram lavadas seis vezes com água destilada esterilizada. No momento da semeadura, com cinco sementes por vaso, $1 \mathrm{~mL}$ de meio 79 semi-sólido, com as estirpes na fase log de seu crescimento (quatro dias de cultivo a $28^{\circ} \mathrm{C}$ ), foi colocado junto a cada semente.

A superfície do vaso foi coberta com uma fina camada de mistura esterilizada de areia, benzeno e parafina, na proporção de 5:1:0,015, respectivamente, com a finalidade de evitar possíveis contaminações. Os níveis de solução nos vasos foram repostos, periodicamente, com solução autoclavada. Decorridos três a cinco dias da germinação, foi feito o desbaste, deixando-se duas plantas por vaso.

As plantas foram colhidas no estágio de florescimento, para determinação da matéria seca da parte aérea e avaliação do número e peso de nódulos secos. Após o destacamento manual, os nódulos das raízes foram contados, e assim como a parte aérea, foram acondiciona- 
dos em sacos de papel e levados para uma estufa de circulação forçada $\left(65^{\circ} \mathrm{C}\right.$ a $\left.70^{\circ} \mathrm{C}\right)$ até massa constante, para determinação da massa da matéria seca. A eficiência relativa de cada tratamento foi calculada segundo a fórmula (Bergensen et al., 1971):

$\mathrm{ER}=($ MSPA inoculada/MSPA com N) $\mathrm{x} 100$, em que ER é a eficiência relativa; MSPA inoculada é a matéria seca da parte aérea da planta com inoculação; e MSPA com N é a matéria seca da parte aérea da planta com $\mathrm{N}$ mineral.

O nitrogênio (N) total foi analisado pelo método semimicrokjedahl, de acordo com Sarruge \& Haag (1979), tendo-se determinado a porcentagem de $\mathrm{N}$ na matéria seca. $\mathrm{O} \mathrm{N}$ acumulado na parte aérea foi calculado com a multiplicação da massa da matéria seca da parte aérea (g) pela porcentagem de N.

Os dados foram analisados, estatisticamente, com o programa SISVAR versão 4.3. Os efeitos dos tratamentos foram comparados pelo teste de Scott-Knott a 5\% de probabilidade.

\section{Resultados e Discussão}

Foi possível agrupar as estirpes que apresentaram perfil protéico semelhante em 11 grupos, conforme Tabela 4 e Figuras 1 e 2. Onze estirpes não se agruparam visualmente com os demais grupos. O perfil protéico das estirpes UFLA03-170, UFLA04-1521 (M3), UFLA04-1417 (F2), UFLA04-1413 (F2) e UFLA04-1406 (F2) não foi revelado no gel. O grupo 1 foi formado por estirpes somente do SUT monocultura, UFLA04-151 (M1) e UFLA04-230 (M2); o grupo 2 por estirpes do SUT capoeira, UFLA04-337 (C1) e UFLA04-355 (C1); o grupo 9 com as estirpes UFLA04-849 (P2) e UFLA04-885 (P2) do SUT pastagem; e o grupo 11 apenas por estirpes do SUT - sistema agroflorestal, UFLA04-903 (A1), UFLA04-917 (A1), UFLA04-918 (A1), UFLA04-924(A1) e UFLA04-926 (A1). O grupo 6 foi formado pelas estirpes UFLA04-958 (A1), UFLA04-1272 (P3) e pela estirpe de referência SEMIA 5019/BR 29 Bradyrhizobium elkanii, recomendada como inoculante para a soja. Os demais grupos foram formados por estirpes de diferentes SUT.

Considerando-se que existem apenas três espécies de Bradyrhizobium descritas até o momento, B. japonicum, B. elkanii e B. liaoningense, e que vários grupos fenotípicos não se agruparam com estirpes tipo ou referência das duas primeiras espécies, nem apresentaram a característica cultural da terceira (crescimento muito lento), existe uma grande possibilidade de existência de novas espécies no grupo de estirpes estudadas. Resultados semelhantes foram encontrados por Motta (2002), que concluiu que estirpes de Bradyrhizobium, isoladas de área minerada de bauxita reabilitada, apresentam alta diversidade fenotípica e podem também representar novas espécies do gênero.

Moreira et al. (1993) verificaram, mediante análise de proteína total por SDS-PAGE, que a maior parte das estirpes isoladas de espécies florestais da Amazônia e da Mata Atlântica pertencia ao gênero Bradyrhizobium, e que havia grande diversidade dentro desse gênero.

Dupuy et al. (1994) encontraram alta diversidade em estudo com 84 estirpes de Bradyrhizobium, isoladas de Acacia albida do Senegal, por meio da análise de proteína total SDS-PAGE, para determinar a posição taxonômica desses organismos e a relação entre estirpes obtidas na superfície e em profundidade no solo. A maioria das estirpes foi distribuída em 8 grupos eletroforéticos, que continham estirpes representativas de B. japonicum, B. elkanii e Bradyrhizobium sp.

Tabela 4. Grupos de proteína total celular, obtidos por eletroforese em gel de poliacrilamida (SDS-PAGE), de estirpes de Bradyrhizobium isoladas de diferentes sistemas de uso da terra na Amazônia: monoculturas de feijão (M1), mandioca (M2) e arroz (M3), capoeiras (C1, C2 e C3), pastagens (P1, P2 e P3), florestas (F1 e F2) e sistemas agroflorestais (A1 e A2).

\begin{tabular}{cl}
\hline Grupo & \multicolumn{1}{c}{ Estirpes } \\
\hline G1 & UFLA04-151(M1) e UFLA04-230 (M2) \\
G2 & UFLA04-337 (C1) e UFLA04-355 (C1) \\
G3 & UFLA04-212 (M2), UFLA04-824 (P2), UFLA04-957 (A1), \\
& UFLA04-1018 (A2) e UFLA04-1019 (A2) \\
G4 & UFLA04-304 (C1), UFLA04-821 (P2) e UFLA04-1001(A2) \\
G5 & UFLA04-640 (F1) e UFLA04-1309 (C3) \\
G6 & UFLA04-958 (A1), UFLA04-1272 (P3) SEMIA 5019 /BR29; \\
G7 & UFLA04-204 (M2), UFLA04-417 (C2), UFLA04-559 (P1), \\
& UFLA04-225 (M2), UFLA04-314 (C1) e UFLA04-338 (C1) \\
G8 & UFLA04-401 (C2), UFLA04-546 (P1) e UFLA04-8113 (P2) \\
G9 & UFLA04-849 (P2) e UFLA04-885 (P2) \\
G10 & UFLA04-820 (P2) e UFLA04-1020 (A2) \\
G11 & UFLA04-903 (A1), UFLA04-917 (A1), UFLA04-918 (A1), \\
& UFLA04-924 (A1) e UFLA04-926 (A1) \\
Separadas & INPA03-11B (1), UFLA03-84 (2), ATCC 10324 (3), \\
& UFLA04-110 (M1) (4), UFLA04-028 (M2) (5), UFLA04-214 \\
& (M2) (6), UFLA04-321(C1) (7), UFLA04-339(C1) (8), \\
& UFLA04-850 (P2) (9), UFLA04-8118 (P2) (10) e \\
& UFLA04-1332 (C3) (11).
\end{tabular}


As médias de número e matéria seca de nódulos (NN e NSM), de matéria seca da parte aérea (MSPA), eficiência relativa (ER) e acúmulo de $\mathrm{N}$ na parte aérea (ANPA) encontram-se na Tabela 5. Não foi verificada a presença de nódulos nas testemunhas com nitrogênio e sem nitrogênio. As estirpes que tiveram maior número de nódulos foram: UFLA04-0230, UFLA04-0640, UFLA04-0204, UFLA04-0401, UFLA04-0917, UFLA04-1272, UFLA04-1332, UFLA04-1309, UFLA04-0885, UFLA04-0559, UFLA04-0546, UFLA04-1020, UFLA04-1417, UFLA04-0314, UFLA04-1001, com as estirpes referência INPA03-11B, UFLA03-170 e UFLA03-84. Todas aquelas estudadas aumentaram o crescimento das plantas em relação ao controle (testemunha sem nitrogênio e sem inoculação).
As estirpes que induziram à maior produção de matéria seca da parte aérea encontram-se na Tabela 5. Essas apresentaram MSPA semelhantes às das referências UFLA03-84 e INPA03-11B, recomendadas para caupi (Magalhães, 1986; Lacerda et al., 2004), e podem representar potenciais estirpes inoculantes.

As estirpes, UFLA04-0110,UFLA04-1309, UFLA04-0885, UFLA04-0559, UFLA04-0546, UFLA04-0321, UFLA04-1020, UFLA04-1417, UFLA04-0314, UFLA04-1001 e as estirpes de referência INPA03-11B, UFLA03-170 e UFLA03-84 tiveram eficiência relativa similar à da testemunha que recebeu nitrogênio (210 mg de N por vaso). As estirpes: UFLA04-1020, UFLA041417, UFLA04-0314, UFLA04-1001 e a estirpe de referência UFLA03-84 induziram ao acúmulo de nitrogê-

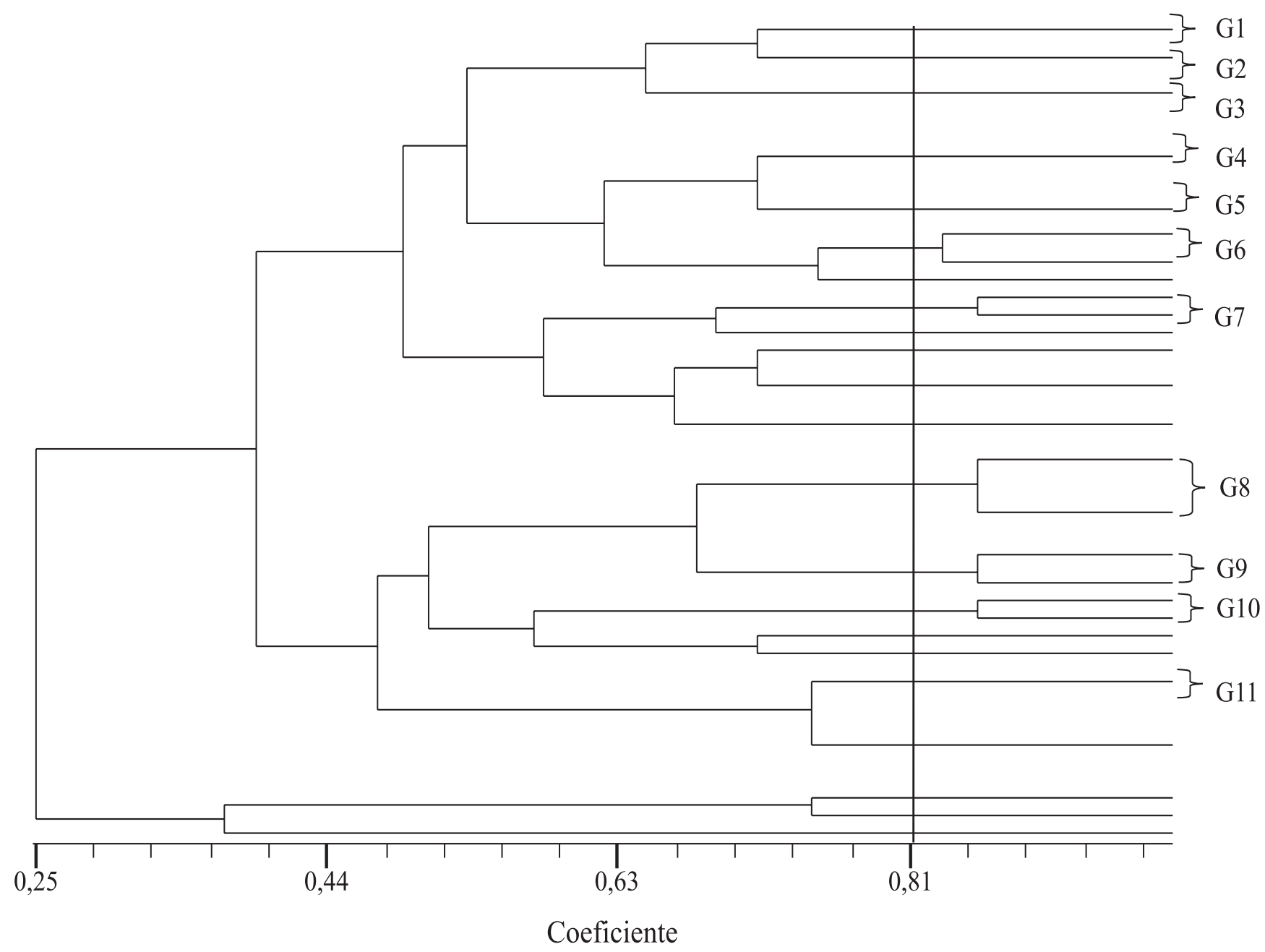

Figura 1. Dendrograma de similaridade, construído com base no perfil protéico total (SDS-PAGE) das estirpes estudadas e das estirpes tipo e de referência. 
nio na parte aérea (ANPA) superior à da testemunha nitrogenada (210 mg de $\mathrm{N}$ por vaso). Uma dessas estirpes, a UFLA04-1417, foi isolada da diluição $5^{-5}$ e, portanto, ocorria em números elevados no SUT de onde foi isolada (floresta). Houve correlação significativa a 1\% entre MSPA e MSN $(r=0,56)$ e entre MSN e ANPA $(r=0,48)$.

Todas as estirpes proporcionaram valores de NN, MSN, MSPA, ER e ANPA superiores aos apresentados pela estirpe BR2001/SEMIA 6145 recomendada pela Relare (2004) até 2004. Resultados semelhantes foram encontrados em outros trabalhos (Martins et al., 1997; Pereira, 2000; Motta, 2002; Lacerda et al., 2004), que indicaram a baixa eficiência da BR2001/SEMIA 6145 e melhor eficiência simbiótica de outras estirpes de rizóbio.

Os grupos eletroforéticos obtidos possuíam estirpes com eficiência variada e oriundas de diferentes SUT, ou seja, não houve relação entre os agrupamentos fenotípicos e simbióticos. Isto pode ser explicado pelo fato de que as proteínas totais representam a expressão de todo o genoma funcional bacteriano, enquanto a eficiência está relacionada a alguns genes específicos. A ocorrência de estirpes diversas e comuns, em diferentes SUT, indica tanto um alto nível de dispersão, como um certo endemismo nesse grupo de bactérias na Amazônia.
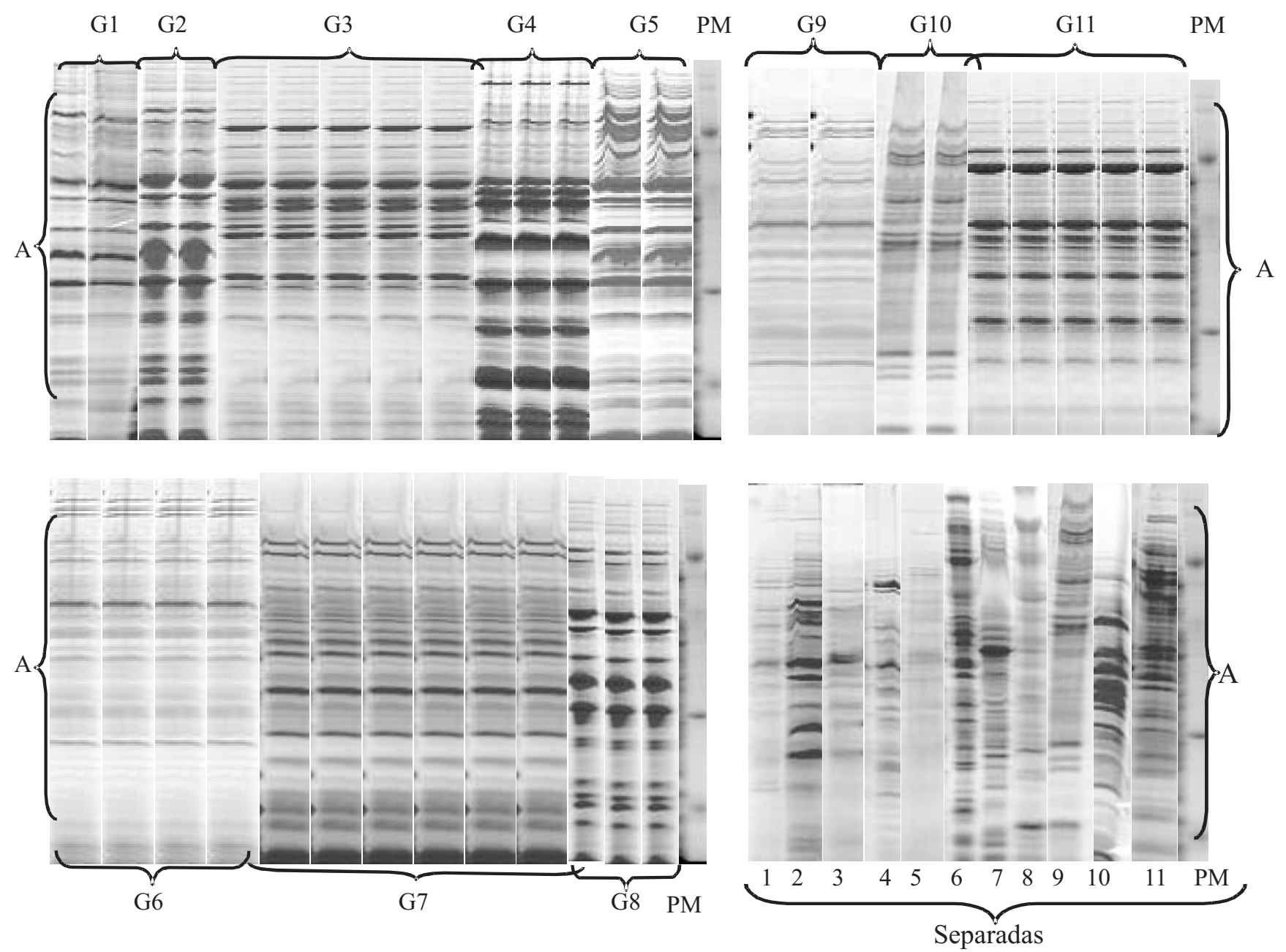

Figura 2. Perfis de proteína celular total, de estirpes isoladas de solos da Amazônia, sob diferentes sistemas de uso da terra, e das estirpes tipo e de referência obtidas por eletroforese em gel de poliacrilamida (SDS-PAGE). A: área utilizada de 13 bandas; PM: padrão de peso molecular LMWM. 
Tabela 5. Número (NN) e matéria seca de nódulos (MSN), matéria seca da parte aérea (MSPA), eficiência relativa (ER) e acúmulo de nitrogênio na parte aérea (ANPA) em caupi com inoculação de rizóbio, com N mineral e sem N mineral, cultivado em vasos de Leonard ${ }^{(1)}$.

\begin{tabular}{|c|c|c|c|c|c|c|}
\hline Formas de $\mathrm{N}$ & $\mathrm{SUT}^{(2)}$ & NN & MSN (g) & MSPA (g) & ER (\%) & ANPA $\left(\right.$ g planta $\left.^{-1}\right)$ \\
\hline Sem N & - & $0 \mathrm{c}$ & $0,00 \mathrm{~d}$ & $0,49 \mathrm{c}$ & $4,08 \mathrm{c}$ & $0,020 \mathrm{~d}$ \\
\hline BR2001 & $\mathrm{R}$ & $282 b$ & $0,50 \mathrm{c}$ & $3,74 \mathrm{~b}$ & $31,17 b$ & $0,119 \mathrm{c}$ \\
\hline UFLA04-0230 & M2 & $514 \mathrm{a}$ & $0,66 \mathrm{c}$ & $5,64 \mathrm{~b}$ & $47,00 \mathrm{~b}$ & $0,119 \mathrm{c}$ \\
\hline UFLA04-0926 & A1 & $438 b$ & $0,62 \mathrm{c}$ & $5,38 \mathrm{~b}$ & $44,83 b$ & $1,152 \mathrm{c}$ \\
\hline UFLA04-0151 & M1 & $310 \mathrm{~b}$ & $0,75 \mathrm{c}$ & $5,17 \mathrm{~b}$ & $43,08 \mathrm{~b}$ & $0,155 \mathrm{c}$ \\
\hline UFLA04-0640 & F1 & $674 a$ & $0,69 \mathrm{c}$ & $5,71 \mathrm{~b}$ & $47,58 \mathrm{~b}$ & $0,166 \mathrm{c}$ \\
\hline UFLA04-0204 & M2 & $663 a$ & $0,93 \mathrm{c}$ & $8,36 \mathrm{~b}$ & $69,67 \mathrm{~b}$ & $0,178 \mathrm{c}$ \\
\hline UFLA04-0401 & $\mathrm{C} 2$ & $682 \mathrm{a}$ & $1,26 \mathrm{~b}$ & $7,30 \mathrm{~b}$ & $60,83 b$ & $0,188 \mathrm{c}$ \\
\hline UFLA04-0917 & A1 & $693 \mathrm{a}$ & $1,46 \mathrm{a}$ & $5,50 \mathrm{~b}$ & $45,83 \mathrm{~b}$ & $0,189 \mathrm{c}$ \\
\hline UFLA04-1521 & M3 & $369 b$ & $0,61 \mathrm{c}$ & $6,41 \mathrm{~b}$ & $53,42 \mathrm{~b}$ & $0,202 \mathrm{c}$ \\
\hline UFLA04-1413 & F2 & $331 b$ & $1,03 \mathrm{~b}$ & $6,10 \mathrm{~b}$ & $50,83 \mathrm{~b}$ & $0,221 \mathrm{c}$ \\
\hline UFLA04-0849 & P2 & $452 \mathrm{~b}$ & $1,15 \mathrm{~b}$ & $8,36 \mathrm{~b}$ & $69,67 b$ & $0,253 \mathrm{c}$ \\
\hline UFLA04-1272 & P3 & $597 \mathrm{a}$ & $0,86 \mathrm{c}$ & $8,94 \mathrm{~b}$ & $74,50 \mathrm{~b}$ & $0,267 \mathrm{c}$ \\
\hline UFLA04-1332 & $\mathrm{C} 3$ & $526 \mathrm{a}$ & $0,74 \mathrm{c}$ & $8,35 \mathrm{~b}$ & $69,58 \mathrm{~b}$ & $0,276 \mathrm{c}$ \\
\hline INPA03-11B & $\mathrm{R}$ & $753 a$ & $1,63 \mathrm{a}$ & $9,97 \mathrm{a}$ & $83,08 \mathrm{a}$ & $0,206 \mathrm{c}$ \\
\hline UFLA04-0110 & M1 & $378 b$ & $0,82 \mathrm{c}$ & $10,48 \mathrm{a}$ & $87,33 \mathrm{a}$ & $0,293 b$ \\
\hline UFLA04-1309 & $\mathrm{C} 3$ & $709 a$ & $0,67 \mathrm{c}$ & $10,44 a$ & $87,00 \mathrm{a}$ & $0,299 \mathrm{~b}$ \\
\hline UFLA03-170 & $\mathrm{R}$ & $607 \mathrm{a}$ & $1,26 \mathrm{~b}$ & $13,00 \mathrm{a}$ & $108,33 \mathrm{a}$ & $0,311 b$ \\
\hline UFLA04-0885 & P2 & $580 \mathrm{a}$ & $1,48 \mathrm{a}$ & $10,74 \mathrm{a}$ & $89,50 \mathrm{a}$ & $0,317 b$ \\
\hline UFLA04-0559 & P1 & $801 \mathrm{a}$ & $1,29 \mathrm{~b}$ & $10,95 \mathrm{a}$ & $91,25 \mathrm{a}$ & $0,359 b$ \\
\hline UFLA04-0546 & P1 & $596 \mathrm{a}$ & $1,83 \mathrm{a}$ & $11,49 a$ & $95,75 \mathrm{a}$ & $0,370 \mathrm{~b}$ \\
\hline Com N & - & $0 \mathrm{c}$ & $0 \mathrm{~d}$ & $12,00 \mathrm{a}$ & $100,00 \mathrm{a}$ & $0,377 b$ \\
\hline UFLA04-0321 & $\mathrm{C} 1$ & $468 \mathrm{~b}$ & $1,54 \mathrm{a}$ & $12,15 \mathrm{a}$ & $101,25 \mathrm{a}$ & $0,378 b$ \\
\hline UFLA04-1020 & A2 & $707 a$ & $1,05 \mathrm{~b}$ & $10,01 \mathrm{a}$ & $83,42 \mathrm{a}$ & $0,409 a$ \\
\hline UFLA04-1417 & F2 & $516 \mathrm{a}$ & $1,61 \mathrm{a}$ & $13,43 \mathrm{a}$ & $111,92 \mathrm{a}$ & $0,444 a$ \\
\hline UFLA04-0314 & $\mathrm{C} 1$ & $725 \mathrm{a}$ & $1,05 \mathrm{~b}$ & $12,17 \mathrm{a}$ & $101,42 \mathrm{a}$ & $0,475 \mathrm{a}$ \\
\hline UFLA03-84 & $\mathrm{R}$ & 871a & $1,16 \mathrm{~b}$ & $13,06 \mathrm{a}$ & $108,25 \mathrm{a}$ & $0,490 \mathrm{a}$ \\
\hline UFLA04-1001 & A2 & $552 \mathrm{a}$ & $1,40 \mathrm{a}$ & $14,19 \mathrm{a}$ & $118,25 \mathrm{a}$ & $0,497 \mathrm{a}$ \\
\hline
\end{tabular}

${ }^{(1)}$ Médias seguidas da mesma letra, nas colunas, não diferem entre si pelo teste de Scott-Knott a 5\% de probabilidade. (2)Sistemas de uso da terra (SUT) na Amazônia: monoculturas de feijão (M1), mandioca (M2) e arroz (M3), capoeiras (C1, C2 e C3), pastagens (P1, P2 e P3), florestas (F1 e F2) e sistemas agroflorestais (A1 e A2); R: estirpes referência.

\section{Conclusões}

1. As 46 estirpes avaliadas apresentam alta diversidade fenotípica (SDS-PAGE), e distribuem-se em 11 grupos com similaridade superior a $80 \%$, dos quais apenas um grupo contém a estirpe referência de B. elkanii: BR29, recomendada como inoculante para a soja.

2. Não há relação entre os agrupamentos fenotípicos baseados nos padrões protéicos e na eficiência simbiótica, assim como, entre esses agrupamentos e os sistemas de uso da terra de origem das estirpes.

3. As populações nativas são constituídas por estirpes com eficiência variável, das quais algumas podem ser recomendadas para testes de eficiência agronômica.

\section{Agradecimentos}

Ao Programa das Nações Unidas para o Desenvolvimento (PNUD), pelo financiamento (GEF/
UNDP) deste trabalho, no âmbito do projeto "Alternatives to Slash-and-Burn" do "International Center for Research in Agroforestry" e do "Tropical Soil Biology and Fertility Programme” (ASB/ICRAF/ TSBF); à Fapemig e ao CNPq, pela concessão de bolsas de M.Sc., IC e Produtividade de Pesquisa aos autores.

\section{Referências}

BERGENSEN, F.J.; BROCKWELL, J.; GIBSON, A.H.; SCHWINGHAMER, E.A. Studies of natural populations and mutants of Rhizobium in the improvement of legume inoculants. Plant and Soil, v.46, p.3-16, 1971. (Supplement, 1).

BRITO, M. de M.P. Marcha de absorção do nitrogênio do solo, do fertilizante e da fixação simbiótica em caupi (Vigna unguiculata (L.) Walp.) e feijão comum (Phaseolus vulgaris L.) determinada usando ${ }^{15}$ N. 1992. 197p. Dissertação (Mestrado) Escola Superior de Agricultura Luiz de Queiroz, Piracicaba.

DREYFUS, B.; GARCIA, J.L.; GILLIS, M. Characterization of Azorhizobium caulinodans gen. nov., a stem-nodulating nitrogenfixing bacterium isolated from Sesbania rostrata. International Journal of Systematic Bacteriology, v.38, p.89-98, 1988. 
DUPUY, N.; WILLEMS, A.; POT, B.; DEWETTINCK, D.; VANDENBRUAENE, I. Phenotypic and genotypic characterization of Bradyrhizobia nodulating the leguminous tree Acacia albida. International Journal of Sistematic Bacteriology, v.44, p.461-473, 1994.

FRED, E.B.; WAKSMAN, S.A. Laboratory manual of general microbiology. New York: McGraw-Hill, 1928. 143p.

JACKMAN, P.J.H. Bacterial taxonomy based on electrophoretic whole-cell protein patterns. In: GOODFELLOW, M.; MINNIKIN, D. (Ed.). Chemical methods in bacterial systematics. London: Academic, 1985. p.119-129.

KAMPFER, P. Differentiation of Brevibacterium species by electrophoretic protein patterns. Systematic and Applied Microbiology, v.17, p.533-535, 1995.

KELLER, G. Isozymes in isolates of Suillus species from Pinus cembra L. New Phytologist, v.120, p.351-358, 1992.

KENNEDY, A.C.; PAPENDICK, R.I. Microbial characteristics of soil quality. Journal of Soil and Water Conservation, v.50, p.243248, 1995.

LACERDA, A.M.; MOREIRA, F.M.S.; MAGALHÃES, F.M.M.; ANDRADE, M.J.B. de; SOARES, A.L. de E.L. Efeito de estirpes de rizóbio sobre a nodulação e produtividade do feijão caupi. Revista Ceres, v.51, p.67-82, 2004.

LAEMMLI, U.K. Cleavage of structural proteins during the assembly of the head of bacteriophage T4. Nature, v.227, p.680-685, 1970.

LAJUDIE, P. de; WILLEMS, A.; NICK, G.; MOREIRA, F.; MOLOUBA, F.; HOSTE, B.; TORCK, U.; NEYRA, M.; COLLINS, M.D.; LINDSTROM, K.; DREYFUS, B.; GILLIS, M. Characterization of tropical tree rhizobia and description of Mesorhizobium plurifarium sp. nov. International Journal of Systematic Bacteriology, v.48, p.369-382, 1998.

LEWIN, A.; ROSENBERG, C.; MEYER, H.Z.A.; WONG, C.H.; NELSON, L.; MANEN, J.F.; STANLEY, J.; DOWLING, D.N.; DÉNARIE, J.; BROUGHTON, W.J. Multiple host-specificity loci of the broad host-range Rhizobium sp. NGR234 selected using the widely compatible legume Vigna unguiculata. Plant Molecular Biology, v.8, p.447-459, 1987.

MAGALHÃES, F.M.M. O estado atual do conhecimento sobre fixação biológica de nitrogênio na Amazônia. In: SIMPÓSIO DO TRÓPICO ÚMIDO, 1., Belém, 1984. Anais. Belém: EmbrapaCPATU, 1986. p.499-512.

MARTINS, L.M.V.; NEVES, M.C.P.; RUMJANEK, N.G. Growth characteristics and symbiotic efficiency of rhizobia isolated from cowpea nodules of the Northeast region of Brazil. Soil Biology and Biochemistry, v.29, p.1005-1010, 1997.

MARTINS, L.M.V.; XAVIER, G.R.; RANGEL, F.W.; RIBEIRO, J.R.A.; NEVES, M.C.P.; MORGADO, L.B.; RUMAJANEK, N.G. Contribution of biological nitrogen fixation to cowpea: a strategy for improving yield in the Semi-Arid region of Brazil. Biology and Fertility of Soils, v.38, p.333-339, 2003.
MOREIRA, F.M.S.; GILLIS, M.; POT, B.; KERSTERS, K.; FRANCO, A.A. Characterization of rhizobia isolated from different divergence groups of tropical Leguminosae by comparative polyacrilamide gel electrophoresis of their total proteins. Systematic and Applied Microbiology, v.16, p.135-146, 1993.

MOREIRA, F.M.S; SIQUEIRA, J.O. Microbiologia e bioquímica do solo. Lavras: Ufla, 2002. 626p.

MOTTA, J.S. Diversidade fenotípica e eficiência simbiótica de estirpes de Bradyrhizobium sp. isoladas de áreas de mineração de bauxita reabilitadas. 2002. 43p. Dissertação (Mestrado) Universidade Federal de Lavras, Lavras.

OLIVEIRA, I.P.; CARVALHO, A.M.A. de. A cultura do caupi nas condições de clima e solo dos trópicos úmidos e semi-áridos do Brasil. In: ARAÚJO, J.P. de; WATT, E.A. (Org.). O caupi no Brasil. Brasília: IITA; Embrapa-SPI, 1988. p.65-95.

PEREIRA E.G. Diversidade de rizóbios isolados em diferentes sistemas de uso da terra na Amazônia. 2000. 93p. Tese (Doutorado) - Universidade Federal de Lavras, Lavras.

PRASAD, P.; BASU, S.; BEHERA, N. A comparative account of the microbiological characteristics of soils under natural forest, grassland and crop field from Eastern India. Plant and Soil, v.175, p.85-91, 1994.

RELARE. Rede de Laboratórios para Recomendação, Padronização e Difusão de Tecnologia de Inoculantes Microbianos de Interesse Agrícola [home page]. Disponível em: <http://www.relare.org.br>. Acesso em: abr. 2004.

SARRUGE, J.R.; HAAG, H.P. Análises químicas em plantas. Piracicaba: Esalq; USP, 1979. 27p.

SOUZA, A.M. de. Diversidade fenotípica e genotípica de isolados de Pisolithus sp. 2000. 107p. Dissertação (Mestrado) - Universidade Federal de Lavras, Lavras.

VANDAMME, P.; POT, B.; FALSEN, E.; KERSTERS, K.; DE LEY, J. Intra and interspecific relationships of veterinary campilobacters revealed by numerical analysis of electrophoretic protein profiles and DND: DNA hybridizations. Systematic and Applied Microbiology, v.13, p.295-303, 1990.

VIEIRA, R.F. Comparações de feijões dos gêneros Vigna e Phaseolus com feijão comum (Phaseolus vulgaris L.). 1989. 213p. Tese (Doutorado) - Universidade Federal de Viçosa, Viçosa.

VINCENT, J.M. Manual for the practical study of root nodule bacteria. Oxford: Blackwell, 1970. 164p.

WILLEMS, A.; DOIGNON-BOURCIER, F.; COOPMAN, R.; HOSTE, B.; DE LAJUDIE, P.; GILLIS, M. AFLP fingerprint analysis of Bradyrhizobium strains isolated from Faidherbia albida and Aeschynomene species. Systematic and Applied Microbiology, v.23, p.137-147, 2000.

Recebido em 10 de setembro de 2004 e aprovado em 11 de abril de 2005 